not as broad as in costata; inner almost spiniform but both flattened. Rest of spurs spiniform.

Not as common as costata and seems to occupy the same range. It has been universally confused with costata in collections.

Holotype: $\hat{\delta}$, Presidio, Texas, June 1-15, 1941, at light (USNM).

Allotype: $q$, eutopotypical (USNM).

Paratypes: 3 ô $\hat{\delta}, 4$ $q$ \% , eutopotypical (USNM).

$1 \hat{o}$, Dog Cañon, Brewster Co., Texas, Sept. 3, 1912 Rehn and Hebard (Phila. Acad.).

1 of , 1 ㅇ, Brewster Co., Texas, D. J. \& J. N. Knull (Ohio State). 1 s., Cloudcroft, Sacramento Mts., New Mexico, July 1, 1940, D. G. Hall (USNM).

1 \%, Roswell, New Mexico, Aug., 1902 (Fall Coll'n., MCZ).

1 \% , Texas Pass, Dragoon Mts., Arizona, July 19, 1917, W. M. Wheeler (MCZ).

\title{
The Female of Neonympha maniola Nabokov
}

(Lepid.-Satyridæ)

Since describing this species (1943, Psyche, 49:68), I have found three specimens of its female (two labelled "Paradise, Ariz.," one "So. Ariz.") in the collection of the United States National Museum. My reference (l.c. pp. 62, 69, 70) to Wright's figures has proved to be correct.

V. Naвokov, Mus. Comp. Zoölogy Cambridge, Mass. 

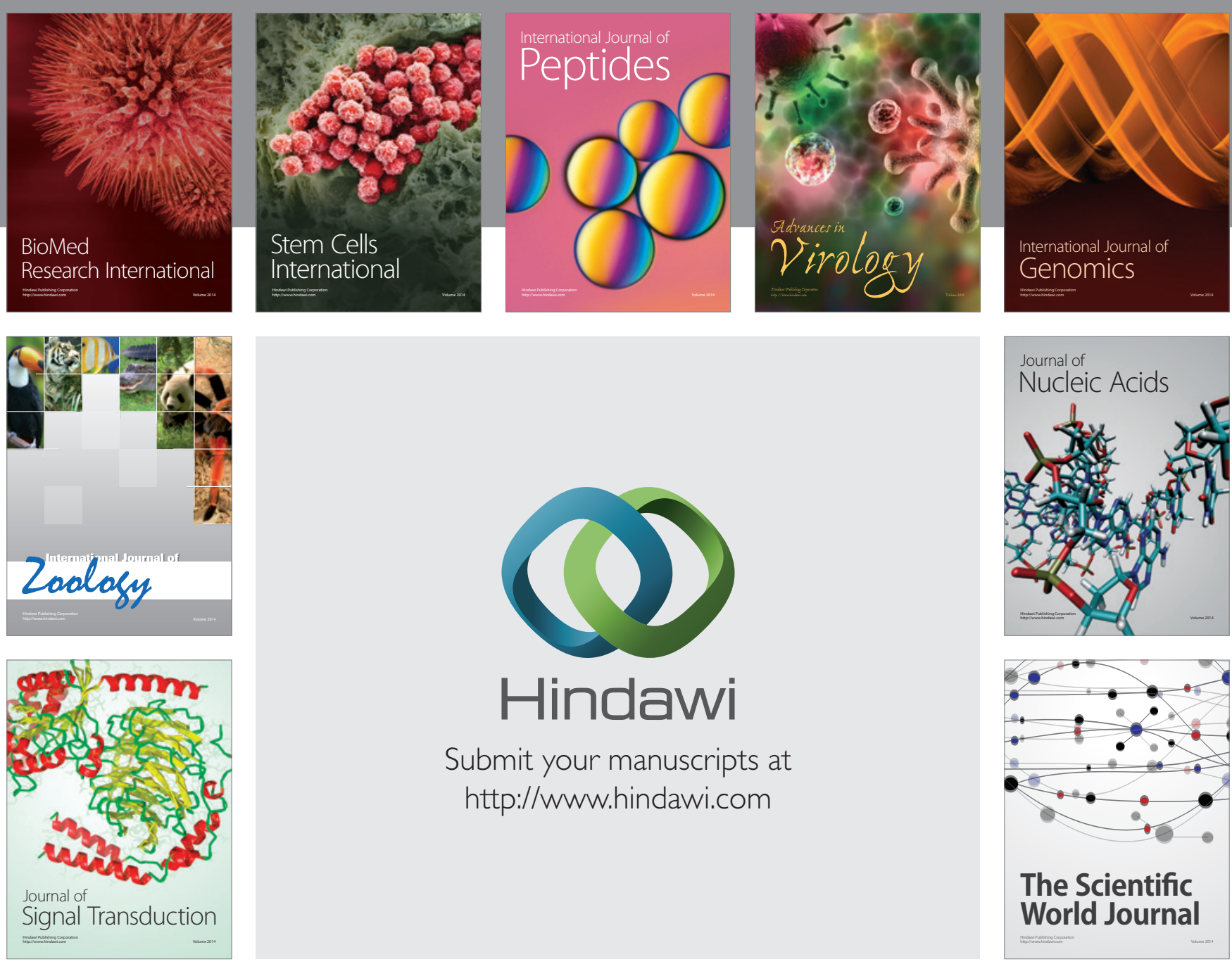

Submit your manuscripts at

http://www.hindawi.com
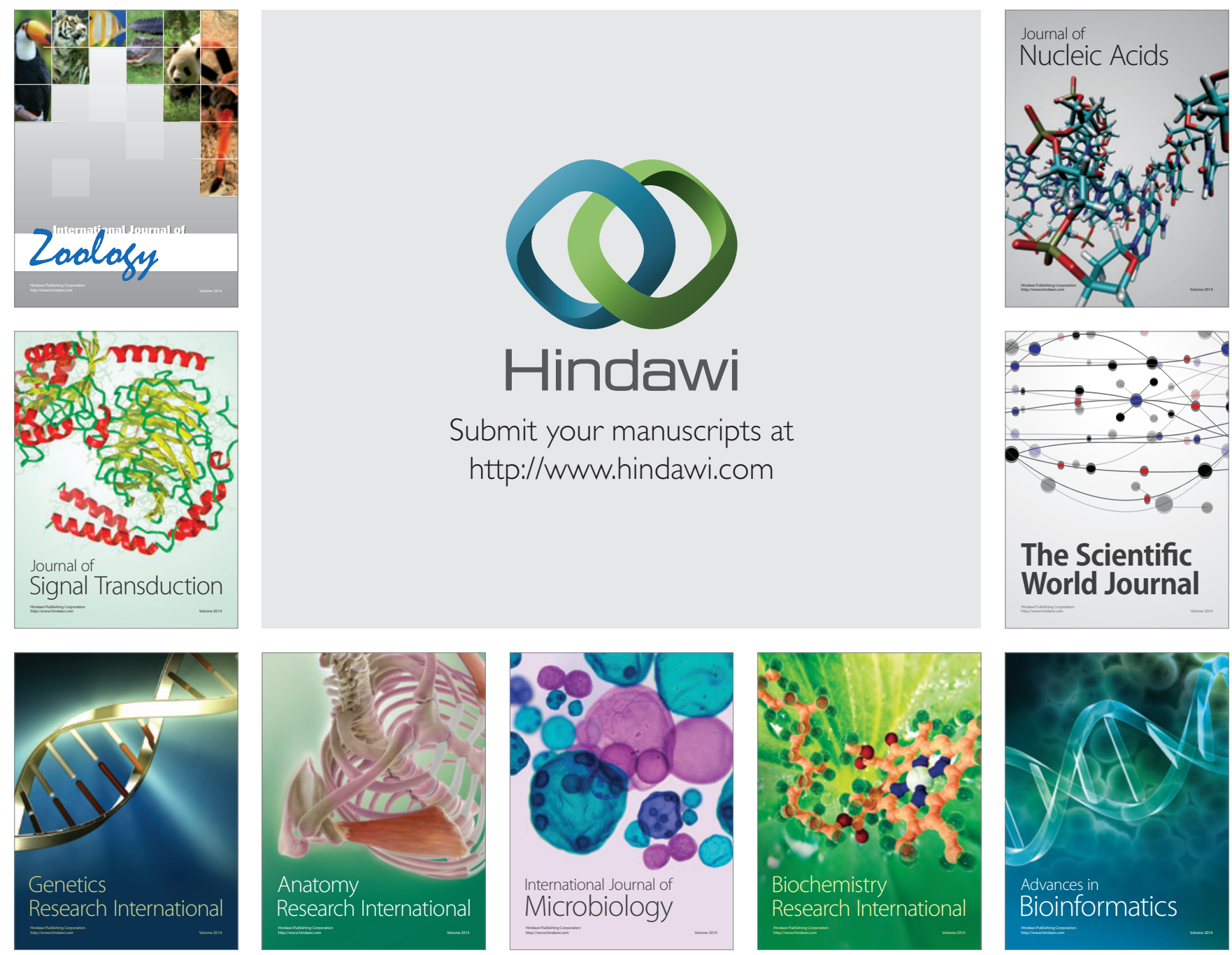

The Scientific World Journal
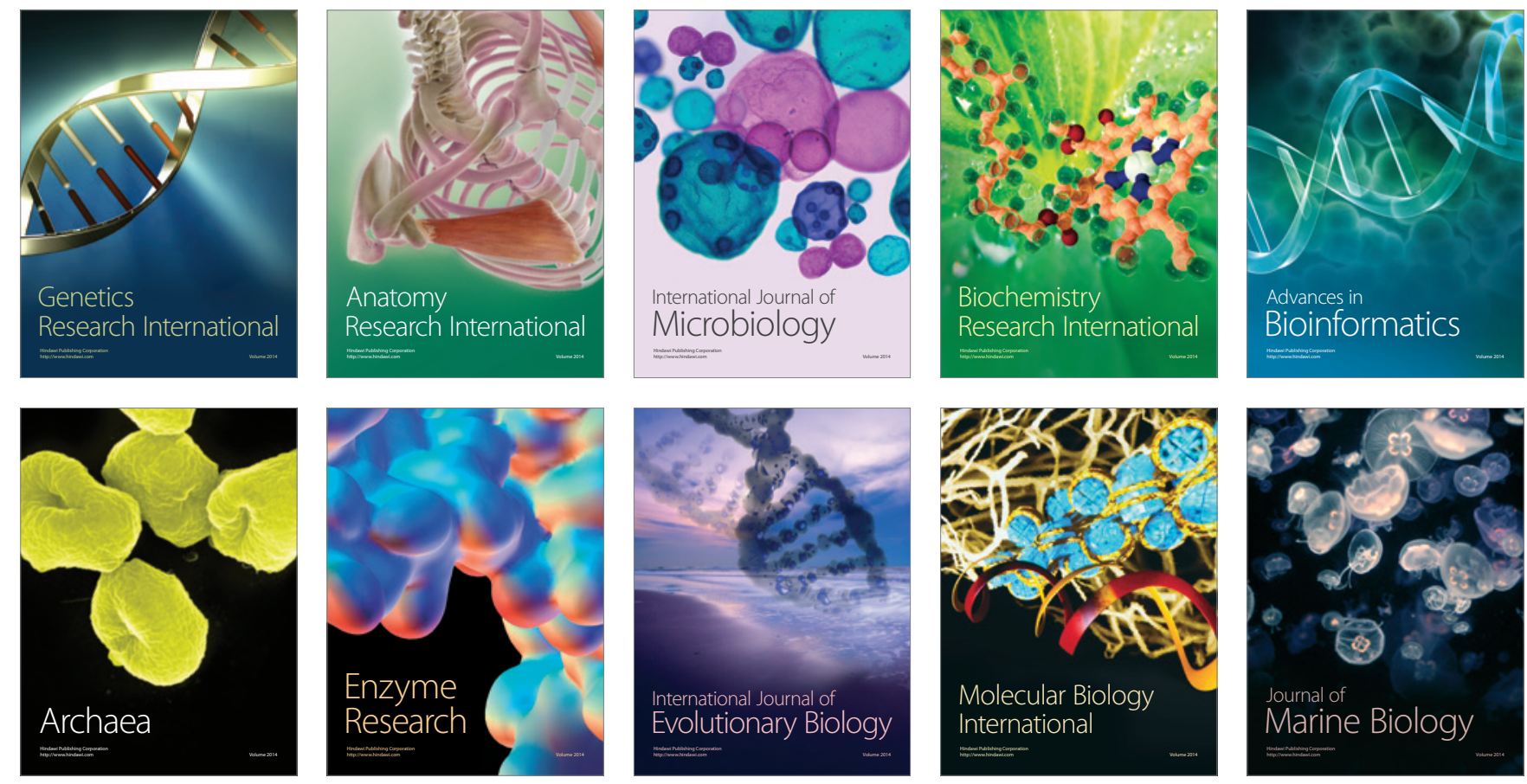